九州大学学術情報リポジトリ

Kyushu University Institutional Repository

\title{
Impact of Salinity Intrusion on Rice Productivity in the Vietnamese Mekong Delta
}

KHAI, Huynh Viet

College of Economics, Can Tho University, Vietnam | Laboratory of Environmental Economics, Department of Agricultural and Resource Economics, Faculty of Agriculture, Kyushu University

DANG, Nguyen Huu

College of Economics, Can Tho University, Vietnam

YABE, Mitsuyasu

Laboratory of Environmental Economics, Department of Agricultural and Resource Economics, Faculty of Agriculture, Kyushu University

https://doi.org/10.5109/1911216

出版情報: 九州大学大学院農学研究院紀要. 63 (1)，pp.143-148，2018-02-27. Faculty of Agriculture, Kyushu University

バージョン：

権利関係 : 


\title{
Impact of Salinity Intrusion on Rice Productivity in the Vietnamese Mekong Delta
}

\author{
Huynh Viet KHAI ${ }^{1}$, Nguyen Huu DANG ${ }^{1}$ and Mitsuyasu YABE*
}

\author{
Laboratory of Environmental Economics, Department of Agricultural and Resource Economics, \\ Faculty of Agriculture, Kyushu University, Fukuoka 812-8581, Japan \\ (Received October 31, 2017 and accepted November 20, 2017)
}

\begin{abstract}
This study conducted a survey with rice farmers in three regions with the same natural environment conditions, social characteristics (e.g. the same social and farming culture, ethnicity, type of soil), and only differed with respect to the level of salinity in Soc Trang province, one of the most salinity-affected areas in the Vietnamese Mekong Delta. The first area is Dai Tam village completely unaffected by salt water intrusion at the period from the end of 2015 to the beginning of 2016, the most heavily salinity-affected time in the Vietnamese Mekong Delta. Two other areas were Lieu Tu and Lich Hoi Thuong village rated as high and very high salinity respectively. The results showed that rice yield loss due to saltwater intrusion was estimated from 2.5 to 4.05 tons $\mathrm{ha}^{-1}$ a year.
\end{abstract}

Key words: Production function, productivity loss, saltwater intrusion, Vietnam

\section{INTRODUCTION}

Climate change has become one of the major threats not only in a country but also urgent issues requiring coordinately resolutions of the world. Vietnam is one of five countries that may be the most seriously affected by global climate change and a consequent rise in sea level. If the sea level rises by between 0.2 and $0.6 \mathrm{~m}, 100-200$ thousand ha of Vietnamese plains will be submerged. A one-meter rise would result in 0.3 to 0.5 million ha of the Red River Delta being submerged and 90\% of the Mekong Delta would be flooded (Danh and Khai, 2014). Moreover, the report by Asia Development Bank (ADB, 2013) showed that Viet Nam was extremely vulnerable to climate change impacts given its extensive coastline and river deltas, and highlands that had poor water retention capacity and were susceptible to severe erosion.

According to the forecast of Ministry of Natural Resources and Environment, Vietnamese Mekong Delta (VMD) provinces will be seriously affected if the sea level rises by one meter. Almost of them would lose from $25 \%$ to $50 \%$ of its land area to flooding. If rivers rise by 0.5-1 m, the waters will reach the height of the current dike system. Due to the impact of a global rise in sea levels, $15,000-20,000 \mathrm{~km}^{2}$ of the VMD's coastal areas would be inundated-nine of its 13 provinces would be completely below water (MONRE, 2009).

Salinity intrusion is a natural phenomenon occurring in the land, estuaries and groundwater adjacent to the sea. Salinity intrusion occurs when there is a difference in the flow of energy as well as specific weight between fresh and salt water. Salinity intrusion is caused by many factors such as river flow levels, topography, geomorphology, the slope of river flow, the intensity of the sea tide, the wind speed and direction, water temperature and so on.

Salinity lands in the Mekong Delta region are rela-

${ }^{1}$ College of Economics, Can Tho University, Vietnam

* Corresponding author (E-mail: yabe@agr.kyushu-u.ac.jp) tively large compared to the whole country due to the crisscrossing systems of river and canals resulting in saltwater easily penetrating further inland. Salinity intrusion lasts longer than normal and penetrates inland about $50 \mathrm{~km}$ if the raining season comes late, and 1\%o salinity covers almost all over the coastal estuaries. Most likely in the peak month, salinity could reach 1.0-1.5\%o. This greatly affects agricultural production, especially rice crop in winter-spring season. In the case of water shortages in the dry season and at the end of the rainy season, people are reluctant to use brackish water to irrigate rice fields, especially in the rice flowering stage, which leads to loss of yield and revenue.

The evidence shows that the agricultural damage of salinity intrusion is not so small in terms of reducing agricultural productivity. Although there have been many studies on evaluating the effects of salinity intrusion in rice production, no studies have evaluated specific statistics about the decline of rice production, estimating an increase in costs and loss of profits caused by salinity. In this study, we analyze the effect of salinity intrusion to rice farmers in terms of rice productivity. The results could provide useful information to local authorities, for example the department of Agriculture and Rural Development, to issue appropriate policies to help or support farmers affected by salinity. The results of the study are also necessary data used as the value of benefit transferring into other similar future studies in Vietnam.

This study is constructed as follows. The next section describes data collection, research area and the approach of production function. The following section reports the results and some discussions related to the impact of rice productivity caused by salinity. The final section presents some main conclusions of the study.

\section{DATA COLLECTION AND RESEARCH AREA}

The study region covers the area of Soc Trang province, one of the most salinity-affected areas in the 
Mekong Delta in 2015. Farmers were randomly selected for interviews from three areas (Dai Tam, Lieu Tu and Lich Hoi Thuong) with the same social, natural condition (e.g. fertile soils, weather) and farming system (e.g. two rice crops per year). The selection of the salinity and non-salinity area are based on the recommendation or suggestion of local authorities and farmers. The villages in Lieu Tu and Lich Hoi Thuong had problems with heavily saltwater intrusion at the period from the end of 2015 to the beginning of 2016, the most heavily salinityaffected time in the Vietnamese Mekong Delta., while the villages in Dai Tam represent the non-salinity area (see Figure 1). In total, 214 rice farmers, consisting of 72 farmers in Lieu Tu and 72 farmers in Lich Hoi Thuong that were affected heavily by salinity and 70 farmers in Dai Tam near Lieu Tu and Lich Hoi Thuong regions, but not affected by salinity. The survey was conducted during the time from March and April 2016. Data was collected on household level information related to production costs and income as well as the social and economic characteristics of the farmers, and their perceived damages and losses due to salinity.

Table 1 shows the salinity level of the study areas during the period of saline intrusion in the Mekong Delta in 2016. The regions of Lieu Tu and Lich Hoi Thuong are rather high salinity, up to $2.8 \%$, while a thousandth part of salt water intrusion in Dai Tam is approximately from 0.0 to $0.3 \%$, which the experts assessed almost not affected by saltwater intrusion. Moreover, to check the validity of the study area, we also asked farmers in these areas whether or not their land is affected by salinity. Almost farmers in Dai Tam answered that salinity have no impacts on their land, while majority of farmers in Lien Tu and Lich Hoi Thuong confirmed that their land had a problem with salinity (See Table 2). This reveals that the selected areas are suitable for the study on yield loss due to salinity.

\section{PRODUCTION FUNCTION APPROACH}

The principle of production function approach is that salinity possibly has a negative impact on the outputs, cost and profit of producers. Production function approach is often used to estimate the effect of environment change on soil erosion, deforestation, fisheries, the impact of air and water pollution on agriculture and so on (Bateman et al., 2003; Reddy and Behera, 2006). Following the study by Khai and Yabe (2012), this

Table 1. The situation of Salinity in the study areas

\begin{tabular}{lcccc}
\hline & Unit & $\begin{array}{c}\text { Non-salinity (Dai } \\
\text { Tam) }\end{array}$ & $\begin{array}{c}\text { Salinity 1 } \\
\text { (Lieu Tu) }\end{array}$ & $\begin{array}{c}\text { Salinity 2 } \\
\text { (Lich Hoi Thuong) }\end{array}$ \\
\hline $\begin{array}{l}\text { Period of salinity } \\
\text { Average level of salinity }\end{array}$ & $\% 0$ & December $12,2015-$ February 2, 2016 \\
\hline
\end{tabular}

Source: Department of Agriculture and Rural Development in My Xuyen and Tran De, 2016

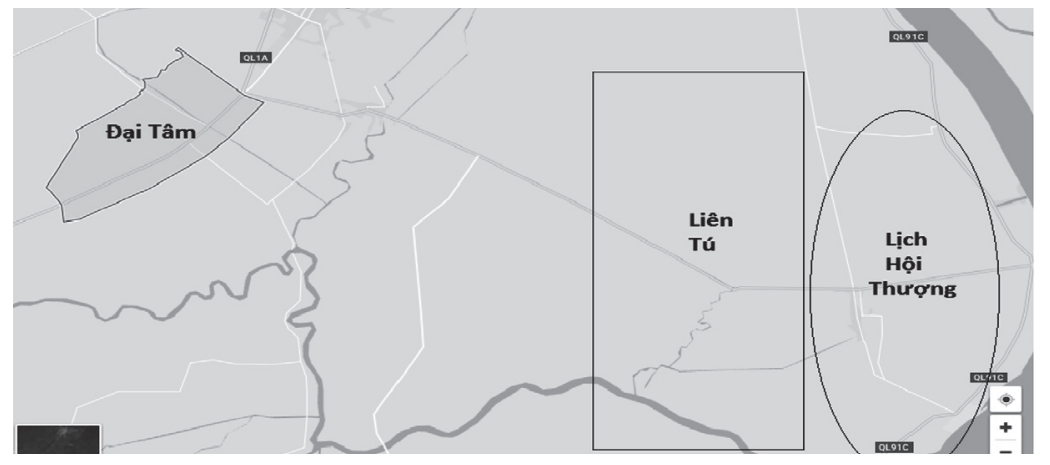

Fig. 1. Map showing study site.

Table 2. Farmers' perception on salinity in study areas

\begin{tabular}{|c|c|c|c|c|c|c|}
\hline & \multicolumn{2}{|c|}{$\begin{array}{l}\text { Non-salinity } \\
\text { (Dai Tam) }\end{array}$} & \multicolumn{2}{|c|}{$\begin{array}{l}\text { Salinity } 1 \\
\text { (Lieu Tu) }\end{array}$} & \multicolumn{2}{|c|}{$\begin{array}{c}\text { Salinity } 2 \\
\text { (Lich Hoi Thuong) }\end{array}$} \\
\hline & Number & Percent (\%) & Number & Percent (\%) & Number & Percent (\%) \\
\hline Rice production is not affected by salinity & 69 & 98.57 & 2 & 2.78 & 3 & 4.17 \\
\hline Rice production is affected by salinity & 1 & 1.43 & 70 & 97.22 & 69 & 95.83 \\
\hline Total & 70 & 100 & 72 & 100 & 72 & 100 \\
\hline
\end{tabular}

Source: Own estimates; data appendix available from authors. 
research uses a translog functional form and does test for checking the existence of Cobb-Douglass. The model takes the basic form:

$$
Y=f\left(L, K, I, Z, E, D_{1}, D_{2}\right)
$$

where $Y$ is the rice yield of a farmer in the studied year (tones/ha), $L$ is the number of labors for rice cultivation (man-days/ha), $K$ is capital input (1,000 VND/ha), $I$ is a vector of material inputs such as seeds ( $\mathrm{kg} / \mathrm{ha})$, fertilizers ( $\mathrm{kg} / \mathrm{ha})$, herbicide ( $\mathrm{ml} / \mathrm{ha}$ ) and pesticides ( $\mathrm{ml} / \mathrm{ha})$, $Z$ is a vector of social-economic characteristics of farmers, and $E$ is a vector of farming conditions, and $D_{1}, D_{2}$ are the relative location of farms $\left(D_{1}=1\right.$ if the farmers in Lieu Tu which is considered as the area little affected by salinity, $D_{2}=1$ if the farmers in Lich Hoi Thuong which is considered as the area heavily affected by salinity; $D_{1}=0$ and $D_{2}=0$ if the farmers in Dai Tam which is considered as the area unaffected by salinity)

The reduced yield of rice is defined as the difference in the average rice yield between the non-salinity and salinity sites. It is estimated by the following equations:

$$
\begin{aligned}
\Delta Y_{1}= & f\left(\bar{L}, \bar{K}, \bar{I}, \bar{Z}, \bar{E}, D_{1}=0, D_{2}=0\right) \\
& -f\left(\bar{L}, \bar{K}, \bar{I}, \bar{Z}, \bar{E}, D_{1}=1, D_{2}=0\right) \\
\Delta Y_{2}= & f\left(\bar{L}, \bar{K}, \bar{I}, \bar{Z}, \bar{E}, D_{1}=0, D_{2}=0\right) \\
& -f\left(\bar{L}, \bar{K}, \bar{I}, \bar{Z}, \bar{E}, D_{1}=0, D_{2}=1\right)
\end{aligned}
$$

where $\Delta Y_{1}$ and $\Delta Y_{2}$ are the average yield losses caused by saltwater intrusion in two salinity areas respectively (kg/ha); $\bar{L}, \bar{K}, \bar{I}, \bar{Z}$ and $\bar{E}$ are the average of labor, capital input, material inputs, social-economic characteristics, and farming conditions, respectively.

As mentioned earlier, a translog functional form is used in the study. The production functional form is written as follows ( Coelli et al., 2005):

$$
\begin{aligned}
\ln (Y) & =\alpha_{0}+\alpha_{1} \ln (L)+\alpha_{2} \ln (K)+\alpha_{3} \ln (I) \\
& +\frac{1}{2} \alpha_{11}(\ln (L))^{2}+\alpha_{12} \ln (L) \ln (K) \\
& +\alpha_{13} \ln (L) \ln (I)+\frac{1}{2} \alpha_{22}(\ln (K))^{2} \\
& +\alpha_{23} \ln (K) \ln (I)+\frac{1}{2} \alpha_{33}(\ln (I))^{2}+\sum_{k=1}^{5} \beta_{K} Z_{K} \\
& +\sum_{k=1}^{3} \delta_{h} E_{h}+\gamma_{1} D_{1}+\gamma_{2} D_{2}+\varepsilon
\end{aligned}
$$

where $Y, L, K, I, D_{1}$ and $D_{2}$ are the same as in the above equations and $Z_{1}, Z_{2}, Z_{3}, Z_{4}$ and $Z_{5}$ are the variables of gender ( 1 = male, 0 = female), experience (years), the number of school year (years), the attendance of trainings ( 1 = Yes, $0=$ No) and family member (persons) of rice households, and $E_{1}, E_{2}$ and $E_{3}$ are the variables of serious diseases happening during the study year $(1=$ Yes, $0=$ No), Irrigation ( $1=$ located in the irrigation region, $0=$ Otherwise $)$ and soil quality ( $1=$ Vey no-fertile, 2 = No-fertile, 3 = Medium, $4=$ Fertile, and $5=$ Very fertile).

Some restrictions are used to check the constant returns to scale:

$$
\begin{aligned}
& \alpha_{1}+\alpha_{2}+\alpha_{3}=1 ; \alpha_{11}+\alpha_{12}+\alpha_{13}=0 \\
& \alpha_{12}+\alpha_{22}+\alpha_{23}=0 ; \alpha_{13}+\alpha_{23}+\alpha_{33}=0
\end{aligned}
$$

Then, the following restriction is applied to test the existence of Cobb-Douglass function:

$$
\alpha_{11}=\alpha_{12}=\alpha_{13}=\alpha_{22}=\alpha_{23}=\alpha_{33}=0
$$

\section{RESULTS AND DISCUSSION}

Table 3 shows the descriptive statistics of main variables in rice production function in the salinity and nonsalinity areas. The column of Salinity 1 represents the group of farmers in Lieu Tu which is considered as the area little affected by salinity while the column of Salinity 2 represents farmers in Lich Hoi Thuong which is considered as the area heavily affected by salinity. Rice yield in Dai Tam (the non-salinity area) is significantly higher than those in the two salinity areas at the level of 1 percent, revealing the existence of the damage of rice production due to salinity. Other factors such as farmers' social-economic characteristics, farming conditions are not so different among the groups of the farmers, showing selected study sites have the same social, natural condition.

The study applies Lagrange Multiplier (LM) test to check the present of Heteroscedasticity in the production function ${ }^{2}$. Because the result shows the existence of Heteroscedasticity in the data at the significant level of 5 percent, we run the regression with robust standard error to solve the problem of Heteroscedasticity. Table 4 shows the OLS result of rice production function with robust standard error in translog form. The coefficients estimated in the model are statistically significant at 1 percent level. The R-square is equal to 0.59 , revealing the 59 percent change of rice yield possibly explained by independent variables in the model.

The study also examines the null hypothesis that there is a proportional output change when inputs in the model are varied or farms produce rice with constant returns to scale. The restricted least squares regression with the null hypothesis of constant returns to scale is conducted. The computed $\mathrm{F}$ statistic is 6.02 higher than the critical value $\mathrm{F}(7,176)$ of 2.06 at 5 percent level of significance ${ }^{3}$. Thus, the null hypothesis is rejected and

\footnotetext{
${ }^{2}$ Breusch-Pagan test for heterscedasticity: $L M=n R^{2} \sim \chi_{k}^{2}$, where: $\mathrm{n}$ is the number of observations; $\mathrm{R}^{2}$ is the R-Square of $\left|\hat{u}_{i}\right|=\hat{\delta_{0}}+\hat{\delta_{1}} X_{1}$ $+\hat{\delta}_{2} X_{2 i}+\cdots+\hat{\delta}_{k} X_{k i}+\hat{v}_{i} ; k$ is the number of restricted factors

${ }^{3}$ Calculated by the formula $F=\frac{\left(S S E_{R}-S S E_{U}\right) / J}{S S E_{U} /(I-K)}$, where $S S E_{R}$ and $S S E_{U}$ are the restricted and unrestricted sums of squared residuals and $\mathrm{J}$ is the number of restrictions
} 
Table 3. Descriptive statistics of rice production per hectare a year

\begin{tabular}{|c|c|c|c|c|c|}
\hline & $\begin{array}{l}\text { Non-salinity } \\
\text { (1) }\end{array}$ & $\begin{array}{l}\text { Salinity } 1 \\
\text { (2) }\end{array}$ & $\begin{array}{l}\text { Salinity } 2 \\
\text { (3) }\end{array}$ & $\begin{array}{l}\text { Difference } \\
\text { (1) vs. (2) }\end{array}$ & $\begin{array}{l}\text { Difference } \\
\text { (1) vs. (3) }\end{array}$ \\
\hline Rice yield (tons) & 13.61 & 11.49 & 8.67 & $2.13^{* * *}$ & $4.94^{* * *}$ \\
\hline Output price (Thousand VND) & 10.16 & 9.51 & 8.00 & $0.646^{*}$ & $2.15 * * *$ \\
\hline Family labor (days) & 23.18 & 30.15 & 20.19 & $-6.97^{*}$ & 2.98 \\
\hline Capital (Thousand VND) & 11,452 & 11,816 & 11,118 & -363.6 & 334.20 \\
\hline Seed (kg) & 293.14 & 388.53 & 383.2 & $-95.4^{* * *}$ & $-90.07 * * *$ \\
\hline Herbicide (ml) & 2.940 .74 & 2.331 .15 & 2.186 .8 & 609.59 & $753.94 * *$ \\
\hline Fertilizer (kg) & $1,145.62$ & $1,128.8$ & $1,056.2$ & 16.86 & 89.43 \\
\hline Pesticide (ml) & $5,203.14$ & $6,784.61$ & $6,348.2$ & $-1,581.5^{*}$ & $-1,145.10$ \\
\hline Training $(1=$ yes, $0=$ no $)$ & 0.64 & 0.46 & 0.42 & $0.18^{*}$ & $0.23 *$ \\
\hline Gender $(1=$ male, $0=$ female $)$ & 0.89 & 0.90 & 0.81 & -0.02 & 0.08 \\
\hline Family member (persons) & 4.37 & 4.57 & 4.85 & -0.198 & $-0.48 * *$ \\
\hline Age (years) & 49.6 & 46.08 & 46.5 & $3.52 * *$ & 3.10 \\
\hline Experience (years) & 28.21 & 26.94 & 26.35 & 1.27 & 1.87 \\
\hline Rice area (ha) & 2.20 & 1.86 & 1.56 & 0.34 & $0.64^{*}$ \\
\hline Diseases $(1=$ yes, $0=$ no $)$ & 0.41 & 0.44 & 0.57 & -0.03 & $-0.155^{*}$ \\
\hline $\begin{array}{l}\text { Soil quality }(1=\text { Vey no-fertile }, 2=\text { no-fertile, } \\
3=\text { Medium, } 4=\text { Fertile, and } 5=\text { Very fertile })\end{array}$ & 3.41 & 2.94 & 2.71 & $0.47^{* * *}$ & $0.71 * * *$ \\
\hline $\begin{array}{l}\text { Irrigation }(1=\text { located in the irrigation region, } \\
0=\text { Otherwise) }\end{array}$ & 0.700 & 0.778 & 0.792 & -0.078 & -0.092 \\
\hline
\end{tabular}

Notes: ***, **, *indicate statistical significance at the 0.01, 0.05 and 0.1 level respectively

Source: Own estimates; data appendix available from authors.

Table 4. The OLS regression of rice production function

\begin{tabular}{|c|c|c|c|c|c|}
\hline Variables & Coef. & Robust Std. Err. & Variables & Coef. & Robust Std. Err. \\
\hline $\ln (L)$ & -0.095 & 0.643 & $\ln \left(I_{p}\right) \ln (K)$ & $0.509 * *$ & 0.149 \\
\hline $\ln (K)$ & 1.945 & 12.198 & $\ln (L) \ln (K)$ & 0.029 & 0.0624 \\
\hline $\ln \left(I_{s}\right)$ & 1.613 & 3.14 & $1 / 2 \ln \left(I_{s}\right)^{2}$ & -0.194 & 0.254 \\
\hline $\ln \left(I_{w}\right)$ & 2.931 & 1.919 & $1 / 2 \ln \left(I_{w}\right)^{2}$ & -0.083 & 0.056 \\
\hline $\ln \left(I_{f}\right)$ & -1.733 & 2.991 & $1 / 2 \ln \left(I_{f}\right)^{2}$ & -0.0655 & 0.216 \\
\hline $\ln \left(I_{p}\right)$ & $-3.211^{* * *}$ & 1.219 & $1 / 2 \ln \left(I_{p}\right)^{2}$ & $-0.108 * * *$ & 0.052 \\
\hline $\ln \left(I_{s}\right) \ln \left(I_{w}\right)$ & 0.0223 & 0.054 & $1 / 2 \ln (L)^{2}$ & 0.315 & 0.0195 \\
\hline $\ln \left(I_{s}\right) \ln \left(I_{f}\right)$ & -0.0945 & 0.868 & $1 / 2 \ln (K)^{2}$ & -0.769 & 1.299 \\
\hline $\ln \left(I_{s}\right) \ln \left(I_{p}\right)$ & $-0.160^{* * *}$ & 0.091 & $Z_{1}$ & 0.023 & 0.039 \\
\hline $\ln \left(I_{s}\right) \ln (L)$ & 0.0114 & 0.043 & $Z_{2}$ & 0.000823 & 0.0015 \\
\hline $\ln \left(I_{s}\right) \ln (K)$ & 0.147 & 0.294 & $Z_{3}$ & -0.013 & 0.024 \\
\hline $\ln \left(I_{w}\right) \ln \left(I_{f}\right)$ & -0.0016 & 0.076 & 24 & $0.059 *$ & 0.029 \\
\hline $\ln \left(I_{w}\right) \ln \left(I_{p}\right)$ & 0.009 & 0.031 & $Z_{5}$ & 0.015 & 0.013 \\
\hline $\ln \left(I_{w}\right) \ln (L)$ & -0.024 & 0.020 & $E_{1}$ & $-0.087 * * *$ & 0.036 \\
\hline $\ln \left(I_{w}\right) \ln (K)$ & -0.263 & 0.181 & $E_{2}$ & $0.141^{* * *}$ & 0.045 \\
\hline $\ln \left(I_{f}\right) \ln \left(I_{p}\right)$ & 0.017 & 0.073 & $E_{3}$ & $0.076 * * *$ & 0.033 \\
\hline $\ln \left(I_{f}\right) \ln (L)$ & -0.078 & 0.050 & $D_{1}$ & $-0.203^{* * *}$ & 0.044 \\
\hline $\ln \left(I_{f}\right) \ln (\mathrm{K})$ & 0.313 & 0.316 & $D_{2}$ & $-0.353 * * *$ & 0.050 \\
\hline $\ln \left(I_{p}\right) \ln (L)$ & $0.050 * * *$ & 0.020 & Constant & -4.320 & 60.730 \\
\hline R-square & \multicolumn{5}{|c|}{0.59} \\
\hline F-statistic & \multicolumn{5}{|c|}{14.14} \\
\hline $\begin{array}{l}\text { Included } \\
\text { observation }\end{array}$ & \multicolumn{5}{|c|}{214} \\
\hline
\end{tabular}

Notes: ***, **, * indicate statistical significance at the 0.01, 0.05 and 0.1 level respectively

Source: Own estimates; data appendix available from authors. 
Table 5. Reduced yield in rice farming caused by salinity

\begin{tabular}{lcc}
\hline & Reduced yield (Tons/ha) & Percentage of reduced yield (\%) \\
\hline Salinity 1 vs. Non-salinity area & 2.502 & 18.382 \\
Salinity 2 vs. Non-salinity area & 4.051 & 29.765 \\
\hline
\end{tabular}

Source: Own estimates; data appendix available from authors.

it is concluded that the technology does not exhibit constant returns to scale.

The second test is applied to check the CobbDouglass formal existence of production function. With the null hypothesis of jointed parameters in equation (5) equal to 0 , the restricted function is estimated. The computed $\mathrm{F}$ statistic of 1.66 is higher than the critical $\mathrm{F}(21,176)$ of 1.62 at 5 percent level of significant ${ }^{2}$. The null hypothesis is rejected and the translog functional form is suitably applied for the data of rice production in the study. The study also shows that there are no multicollineariry in the independent variables of production function because the correlations of these independent variables estimated by using the correlation matrix are less than 70 percent (Khai and Yabe, 2013).

Table 4 performs that the coefficients of $D_{1}$ (Salinity 1) and $D_{2}$ (Salinity 2) variables are significantly negative at 1 percent level, revealing rice productivity in the nonsalinity area is higher than in the salinity areas. The other variables of $Z_{4}$ (Training), $E_{2}$ (Irrigation) and $E_{3}$ (Soil quality) are also significantly positive. Short training courses on 3-reduction and 3-increase, IMP program, guideline of applying new technologies and so on normally given by local extension services partly contribute to an increase in rice yield. It is true for farmers in the irrigation and fertile areas to produce more yield than others in areas without irrigation or low soil quality.

The reduced productivity of rice is calculated based on findings from Table 4. Rice yields in the non-salinity and salinity areas are estimated and then the equation (2) is used to calculate the loss of rice yield due to salinity by subtracting the yield in the non-salinity region from yield in the salinity region. Various yield losses estimated depending on different salinity areas are performed in Table 5. Using this approach, the loss of productivity is calculated to be approximately 2.502 tons per hectare in the site of Salinity 1, which reflects an $18.4 \%$ reduced yield and 4.051 tons in the site of Salinity 2, which is dominated a $29.8 \%$ yield loss.

\section{CONCLUSIONS}

In this study, we surveyed rice farmers in three areas with the same natural environment conditions and social characteristics, and only differed with respect to salinity. The rice productivity loss caused by salinity was estimated by the difference in rice productivity between the three areas. The results showed that the annual productivity loss was about $2.5-4.05$ tons per hectare.

Although official warnings of expected salinity and drought problems during the Dong Xuan season generally reach farmers early, these warnings did not translate into adjusted agricultural production on a large scale. High salinity during the late stage of rice growth (around maturity) was also a major problem during the 2016 salinity crisis. Early cut-off dates for harvesting rice could help farmers avoid stretching the crop into periods of high salinity by late March and April. Suitable shortduration varieties for the adjusted growth window thus need to be identified and promoted. Additional investments should be made to further improve those varieties, and to improve late-stage salinity tolerance. This study only estimated the quantity reduction of rice production due to salinity.

The current salinity crisis has shown that a regional water management approach is crucial for minimizing damage to rice production. This includes better coordination and communication of measures across different provinces of the VMD, as well as strengthening cooperation with other riparian states of the Mekong River. In the long term, all popular varieties planted in the VMD should carry multiples tolerances to abiotic stresses (i.e. salinity, drought and heat stress) and fit for the new cropping system. A forward-looking breeding program should be designed for the development of new 'designer' varieties that fit the new cropping systems and carry the package of traits required for climate resilience, such as combining tolerance to current and foreseen abiotic stresses like salinity, drought and heat stress. These recommendations are also considered in the new rice master plan recently approved by the MARD (Ministry of Agriculture and Rural Development) Minister as part of the Prime Minister's decision (Decision No. 899/QDTTg dated 10 June 2013) to restructure Vietnam's agricultural sector.

\section{AUTHOR CONTRIBUTIONS}

Huynh Viet Khai designed the study questionnaire, collected and analyzed the data, and drafted the manuscript; Nguyen Huu Dang analyzed the data, and drafted the manuscript; and Mitsuyasu Yabe supervised the research and made critical revisions to the manuscript under the Technical Cooperation Project "Building capacity for Can Tho University to be an excellent institution of education, scientific research and technology transfer" of JICA. All authors read and approved the final manuscript. 


\section{ACKNOWLEDGMENTS}

This study is funded in part by the Southeast Asian Regional Center for Graduate Study and Research in Agriculture (SEARCA) and the Technical Cooperation Project "Building capacity for Can Tho University to be an excellent institution of education, scientific research and technology transfer" of JICA. Our warmest thanks go to the staff and students in the department of Environmental and Resource Economics, College of Economics, Can Tho University for assisting in data collection.

\section{REFERENCES}

ADB 2013 Viet Nam: Environment and climate change assessment. Asian Development Bank, Mandaluyong City, Philippines Bateman, I. J., R. T. Carson, B. Day, M. Hanemann, N. Hanley, T. Hett, M. J. Lee, G. Loomes, S. Mourato, Ozdemiroglu E., Pearce
D. W., Sugden R. and Swanson J. 2003 Economic Valuation With Stated Preference Techniques. Edward Elgar Publishing, London

Coelli, T. J., D. S. P. Rao, C. J. O'Donnell and G. E. Battese 2005 An introduction to efficiency and productivity analysis. Springer Science \& Business Media, New York

Danh, V. T. and H. V. Khai 2014 Using a Risk Cost-Benefit Analysis for a Sea Dike to Adapt to the Sea Level in the Vietnamese Mekong River Delta. Climate, 2(2): 78-102

Khai, H. V. and M. Yabe 2012 Rice Yield Loss Due to Industrial Water Pollution in Vietnam. Journal of US-China Public Administration, 9(3): 248-256

Khai, H. V. and M. Yabe 2013 Impact of Industrial Water Pollution on Rice Production in Vietnam. In "International Perspectives on Water Quality Management and Pollutant Control", ed. by Dr. Nigel W. T. Quinn, INTECH publishing, Croatia, pp. 61-85

MONRE 2009 Climate change, sea level rise scenarios for Vietnam. Ministry of Natural Resources and Environment, Hanoi, Vietnam

Reddy, V. R. and B. Behera 2006 Impact of Water Pollution on Rural Communities: An Economic Analysis. Ecological Economics, 58(3): 520-537 